\title{
Virtual laboratory of remote sensing time series: visualization of MODIS EVI2 data set over South America
}

\author{
Ramon Morais de Freitas ${ }^{1}$, Egidio Arai ${ }^{1}$, Marcos Adami ${ }^{1}$, Arley Souza Ferreira ${ }^{1}$, \\ Fernando Yuzo Sato ${ }^{1}$, Yosio Edemir Shimabukuro ${ }^{1}$, Reinaldo Roberto Rosa ${ }^{1}$, \\ Liana Oighenstein Anderson ${ }^{1,2}$ and Bernardo Friedrich Theodor Rudorff ${ }^{1}$
}

Manuscript received on February 4, 2011 / accepted on March 24, 2011

\begin{abstract}
Over the last ten years millions of gigabytes of MODIS (Moderate Resolution Imaging Spectroradiometer) data have been generated which is forcing the remote sensing users community to a new paradigm in data processing for image analysis and visualization of these time series. In this context this paper aims to present the development of a tool to integrate the 10 years time series of MODIS images into a virtual globe to support LULC change studies. Initially the development of a tool for instantaneous visualization of remote sensing time series within the concept of a virtual laboratory framework is described. The virtual laboratory is composed by a data set with more than 500 million EVI2 (Enhanced Vegetation Index 2) time series derived from MODIS 16-day composite data. The EVI2 time series were filtered with sensor ancillary data and Daubechies (Db8) orthogonal Discrete Wavelets Transform. Then EVI2 time series were integrated into the virtual globe using Google Maps and Google Visualization Application Programming Interface functionalities. The Land Use Land Cover changes for forestry and agricultural applications are presented using the proposed time series visualization tool. The tool demonstrated to be useful for rapid LULC change analysis, at the pixel level, over large regions. Next steps are to further develop the Virtual Laboratory of Remote Sensing Time Series Framework by extending this work for other geographical regions, incorporating new computational algorithms, testing data from other sensors and updating the MODIS time series.
\end{abstract}

Keywords: MODIS, EVI2, wavelets transform, time series analysis, virtual globe, land use and land cover changes, forest, agriculture, South America, instantaneous visualization.

\section{INTRODUCTION}

Over the last few decades, multi-temporal images of Earth observation satellites have turned into a paramount source of information for monitoring the planet Earth, particularly to study the land use and land cover changes (LULC) [1]. Such studies are gaining more attention not only by scientists but also by policy makers and media, since terrestrial ecosystems exert major influence on climate change and climate variability [2].

Remote sensing sensors such as: the AVHRR (Advanced Very High Resolution Radiometer) on board of the NOAA (National Oceanic and Atmospheric Administration) satellites; the Vegetation on board of the SPOT (Satellite Pour l'Observation de la Terre) satellites; and the MODIS (Moderate Resolution Imaging

Correspondence to: Ramon Morais de Freitas - E-mail: ramon@dsr.inpe.br

${ }^{1}$ National Institute for Space Research - INPE, São José dos Campos, SP, Brazil.

2University of Oxford, Environmental Change Institute - ECl, Oxford, UK. 
Spectroradiometer) on board of the Terra (EOS-AM1) and Aqua (EOS-PM1) satellites have been responsible for the construction of long term time series dataset. All these sensors acquire images on an almost daily basis which is an important characteristic for optical sensors designed to observe LULC changes. For the MODIS sensor a significant advancement was achieved by improving both spatial and spectral resolutions. Furthermore, an international consortium of scientists has focused on providing validated MODIS data with high radiometric and geometric quality, since the launch of the Terra satellite [3]. Over the last ten years millions of gigabytes of MODIS data have been generated which is forcing the remote sensing users community to a new paradigm in data processing for image analysis and visualization of these long term time series.

On the other hand the development of geobrowser tools, based on virtual globes, has provided free access to high spatial resolution images and geographical maps derived from remote sensing satellites. The development of these virtual globes allowed researchers and general public to visualize geospatial data, to understand multi-scale geography, to process data and to publish information $[4,5,6]$. The visualization of long term remote sensing data sets for scientific purposes has great potential for better understanding the complex space-time dynamics of terrestrial ecosystems. This tool is useful for scientists to understand more efficiently the different phenomena embedded in a large volume of data [7]. However, the pre-processing and extraction of information from these data sets require specific software and advanced technical knowledge to put them available to the end-users in a friendly and accessible way. The integration of time series for studies on LULC changes using virtual globes such as Google Maps (http://maps.google.com/) Google Earth (http://earth.google.com/) and Microsoft Virtual Earth (http://www.microsoft.com/maps/) are not yet easily accessible to users due to constraints in data storage and the lack of a specific computational architecture for integration and visualization of this time-series. In this context, this paper aims to present the development of a tool to integrate the 10 years time series of MODIS images into a virtual globe to support LULC change studies.

\section{THE VIRTUAL LABORATORY OF REMOTE SENSING TIME SERIES}

The macro framework of the Virtual Laboratory of Remote Sensing Time Series is divided into five components that are presented in Figure 1. The Data set component includes the hardware and software structures to storage the remote sensing time series data. The Dataset manager establishes the connections among all the laboratory components. The Algorithm module and the Analysis module provide the basis for the time series analysis and visualization. The Visualization module establishes the interface between the laboratory and the end-user using virtual globe facilities. The Visualization module is the main purpose of the present work and is described using the 10 years of MODIS time series data set.

\subsection{Modis data set}

The present work was developed for the South America continent that comprises about 18 million $\mathrm{km}^{2}$, representing 12\% of the Earth land surface. The region is characterized by different biomes such as tropical and seasonal forest, caatinga forest, grassland, savanna and others (Global Change Biology South America map [8]).

The MODIS images were acquired at the portal Warehouse Inventory Search Tool WIST NASA (https://wist.echo.nasa.gov). The selected product was the MOD13Q1 (collection 5) which is the composition of 16 days at spatial resolution of $250 \mathrm{~m}$. The time frame of data acquisition is July 2000 to December 2010. The study area is divided in 29 MODIS tiles with $1,200 \times$ $1,200 \mathrm{~km}$ each as illustrated in Figure 2. A total of 6,293 tiles were acquired corresponding to $3.5 \mathrm{~TB}$ of raw data. The images are in sinusoidal projection (WGS84 datum). All bands were reprojected to the geographic coordinate system with the same datum and converted from HDF (Hierarchical Data Format) to GeoTIFF format to ensure data portability among software. The total storage capacity is approximately $295 \mathrm{~GB}$ for each time series per spectral band. The vegetation index chosen for the present study is the EVI2 (Enhanced Vegetation Index 2; [9]) which highlights the land cover variations. It is computed using the surface reflectance of the Red and NIR (near infrared) bands available in the MOD13Q1 product (Equation 1):

$$
E V I 2=2.5 * \frac{N I R-\text { Red }}{(N I R+2.4 * \text { Red }+1)}
$$

In addition, the view zenith angle band and the blue band (surface reflectance) were used to pre-filter the MODIS time series as explained in the next section.

\subsection{Filtering Procedures}

Optical remote sensing data are frequently affected by cloud cover and sensor noise that interfere in the ability to characterize spatial-temporal land cover dynamics. In order to construct a 


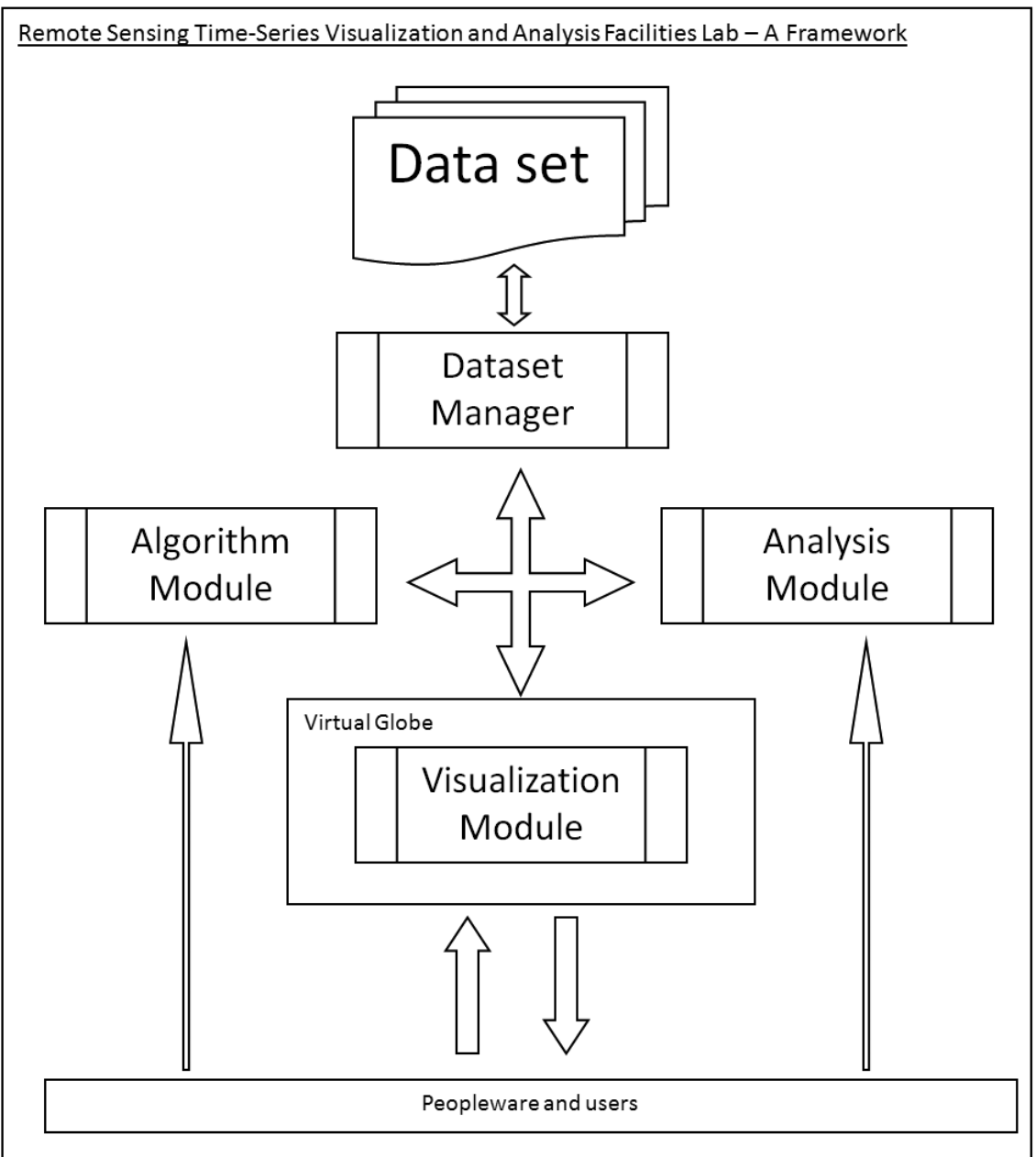

Figure 1 - Virtual Laboratory of Remote Sensing Time Series framework.

continuous and consistent time series it is necessary to filter the data. The filtering procedures were performed in two steps generating two EVI2 time series: 1) without wavelet transform; and 2) with wavelet transform. The first filtering procedure applied rules that were designed following the methodologies proposed by $[10,11]$ in which data were eliminated from the original time series if the reflectance in the blue band is greater than $10 \%$ or if the sensor view zenith angle is greater than $32.5^{\circ}$. These threshold procedures eliminate clouds contaminated and off-nadir pixels. The filtered data were then linear interpolated based on the date of the pixel of the image composition to provide equally spaced time series.

Further filtering was applies in the second filtering procedure using the wavelet transform following the methodology proposed by [12]. The signal decomposition by wavelets eliminates the high frequencies typically associated with the presence of noise. The wavelet transform is given by $[13,14]$ :

$$
\begin{aligned}
& W(a, b)=\int_{-\infty}^{+\infty} f(t) \frac{1}{\sqrt{|a|}} \psi_{a, b} *\left(\frac{t-b}{a}\right) d t \\
& \psi_{a, b}(t) \equiv \frac{1}{\sqrt{a}} \psi \frac{(t-b)}{a}, a>0,-\infty<b<+\infty
\end{aligned}
$$

where $a$ is the scale parameter, $b$ is the translation parameter, $f(t)$ is the function to be transformed and $\psi^{*}$ is the mother wavelet function complex conjugate. The function (Equations 2 and 3) is not continuous; therefore, it needs to be discretized by using discrete values of $(a, b)=\left(2^{m}, 2^{n}, k\right)$, where $m$, $n$ and $k$ are integer values and limited by the length of the time series. This allows the expansion of the mother wavelet to other scales. The Discrete Wavelet Transform (DWT) decomposes a discrete signal at different resolution levels. A DWT, defined in 


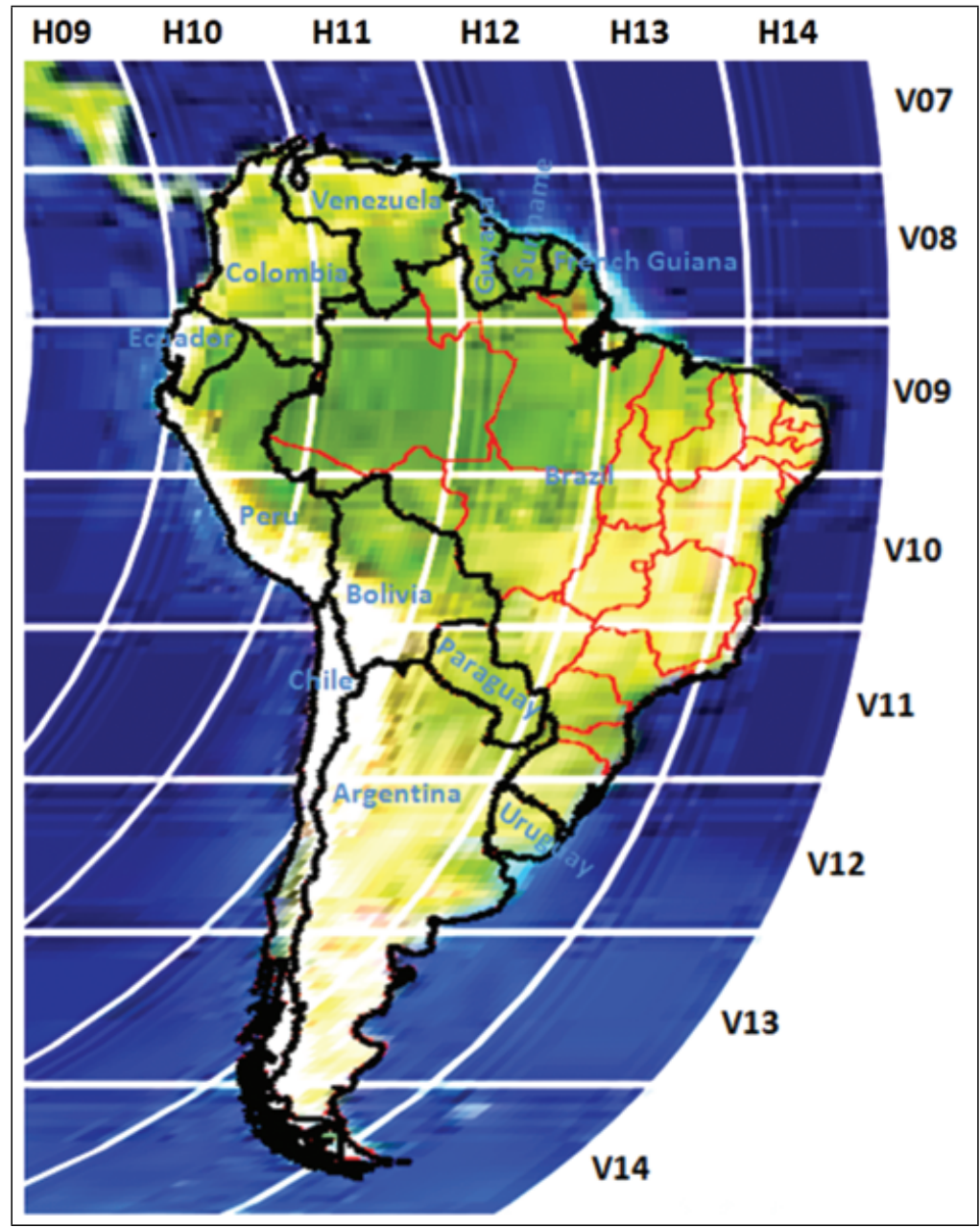

Figure 2 - MODIS tiles coverage for South America.

Equation 4, is a mapping function of a discrete digital signal into a sequence of coefficients

$$
D W T(m, k)=\frac{1}{\sqrt{a_{0}^{m}}} \sum_{n}^{k} x(n) \psi\left(\frac{k-n b_{0} a_{0}^{m}}{a_{0}^{m}}\right)
$$

where $\psi$ is the mother wavelet and the scaling parameters $a$ and $b$ are translation functions of the integer parameter $m$ in which $a=a_{0}^{m}, b=n b_{0} a_{0}^{m}$ and $k$ is an integer variable that refers to the number of samples of a given input signal $(x)$ that depends on the signal length. The parameters $a$ and $b$ allow expanding the mother wavelet into several daughter wavelets.

The implementation of the discrete function (Equations 5, 6 and 7) is performed through recursive algorithms of low pass and high pass frequency filters known as pyramid algorithm [15]. For each decomposed signal in the $j^{t h}$ scale signal there is a ratio coefficient of details $(D)$ given by high-pass filters, and approximations $(A)$ given by low-pass filters associated with the mother wavelet,

$$
\begin{aligned}
& f_{m}(t)=A_{m}(t)+\sum_{j=1}^{m} D_{j}(t), \\
& D_{M}(t)=\sum_{k=-\infty}^{\infty} W_{m, k} \psi_{m, k}(t), \\
& A_{m}(t)=\sum_{k=-\infty}^{\infty} V_{m, k} \varphi_{m, k}(t),
\end{aligned}
$$

where $W_{m, k}$ are the wavelets coefficients, $\varphi_{m, k}$ is a scaled and translated basis function called scaling function and $V_{m, k}$ are the scaling coefficients.

The Daubechies wavelet Db8 was used as mother function (Fig. 3). This function is orthogonal ensuring that the decomposed signal is reconstructed without the presence of residues 


\section{Daubechies Db8 wavelet}

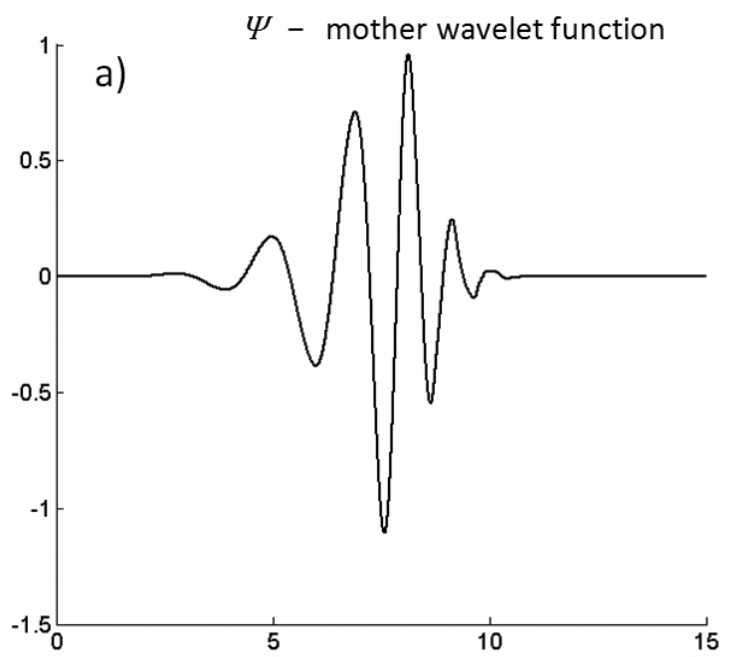

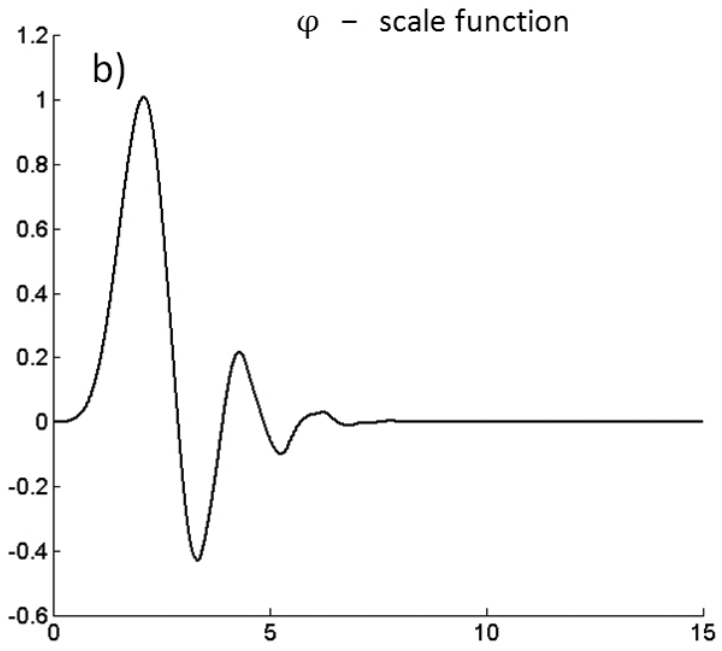

Figure 3 - Wavelets functions: a) Db8 mother wavelet $(\psi)$ and b) Scale function Db8 $(\varphi)$.

due to asymmetries of the wavelet mother function. In this procedure, each set of pixels corresponds to a time series profile of the stacked images. The vector $t$ was broken into 8 different scales and the time series was reconstructed using the five largest scales corresponding to lower frequencies. The higher frequencies were eliminated because they are usually associated with the presence of sensor noise and spectral responses contaminated by clouds and shadows.

The names given to the two EVI2 time series generated by the filtering procedures were:

1) without wavelet, and

2) with wavelet.

\subsection{Data Integration and the Web Tool}

The generated Data set (Fig. 1) is composed by over 500 million EVI2 time series filtered with and without wavelet transform for the entire South America continent. In order to construct this data set a significant computational effort was carried out involving more than 60 days of processing time using three personal computers $(\mathrm{PC})$ with Linux OS. All computational procedures used Matlab and Ansi $C$ platforms.

The EVI2 time series were integrated into the virtual globe (GoogleMaps) using the Dataset manager (Fig. 1) that was specifically developed for this purpose. To visualize the EVI2 time series in the virtual globe a website was built, which is available at http://www.dsr.inpe.br/laf/series.html, based on JavaScript and PHP platforms using Google Maps and Google Visualization
Application Programming Interface functionalities. For each call of a geographic coordinate from the virtual globe the two EVI2 time series are instantaneously recovered. The information of the time series recovered by the call refers to one MODIS pixel. The integration with the virtual globe shows static geographical space using high spatial resolution satellite images provided by Google Maps server (Fig. 4a). However, caution should be taken for analyzing these time series due to the different spatial resoIution of the images. Each MODIS pixel represents roughly an area of 6.25 ha $(250 \times 250 \mathrm{~m})$ while the high spatial resolution image provided by Google Maps is only used to locate the MODIS pixel. In addition, a tool was build to assess the elevation anisotropy around the selected point (red balloon). This tool uses the elevation model information available in the Google maps API. The anisotropy visualization is a simple polar plot of elevation around two sample circles, allowing a rapid view of the topography around the selected point (Fig. 4c). This tool allows interactivity and provides a range of distance between the center of the selected coordinate and the sampled circles. Figure $4 \mathrm{~d}$ shows the 10 years EVI2 time series using interactive plot provided by Google charts API functionalities. The red and blue lines represent the time series filtered with wavelet and without wavelet, respectively.

\section{APPLICATIONS}

The intense anthropogenic pressure forces the LULC change processes in South America by converting natural forest and savanna areas to pasture and agriculture. At sub-tropical region 


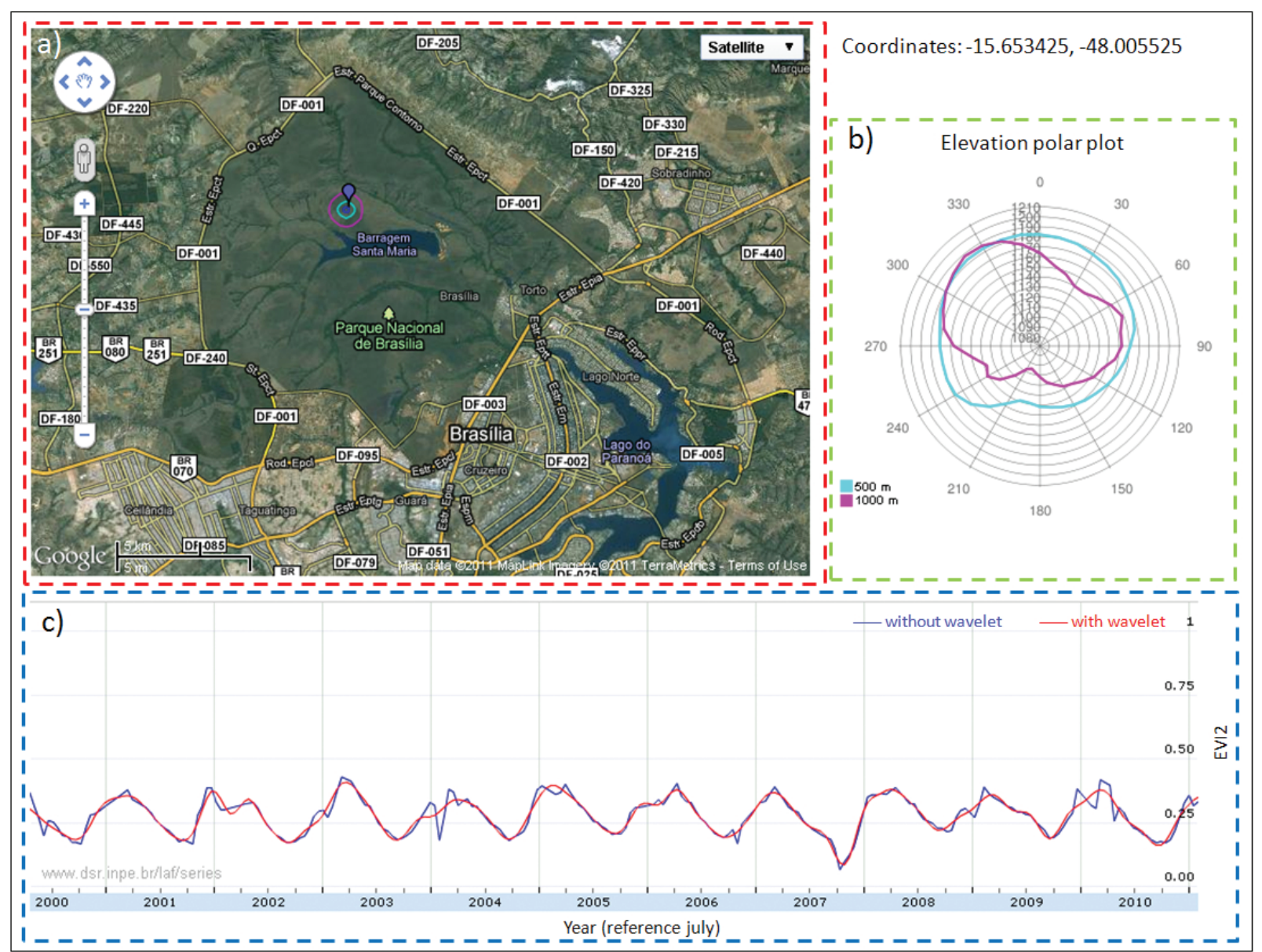

Figure 4 - Website display components: a) Google earth virtual globe used to select the geographic coordinate of the area of interest; b) list of selected points; c) polar plot of elevation around two sampled circles showed in Google image; and d) EVI time series for the selected plot (red line filtered with wavelet and blue line filtered without wavelet).

there is the intensification of agriculture related to food and biofuels production [16, 17]. In this context some application examples are provided using the visualization module described in the present work for LULC change analysis.

\subsection{Land Use and Land Cover Change Over Forest}

Figure 5a shows a forested region with several deforested areas in the municipality of Feliz Natal in Mato Grosso state, Brazil. The elevation around the selected point $\left(11^{\circ} 55^{\prime} \mathrm{S}\right.$; $\left.54^{\circ} 10^{\prime} \mathrm{W}\right)$ varies from 354 to $360 \mathrm{~m}$ indicating a reasonable flat terrain (Fig. 5b). The MODIS EVI2 time series are presented in Figure 5c. Analyzing the time series a decrease in the EVI2 values can be observed in 2004 indicating a significant biomass loss due to the deforestation process. From 2005 to 2007 there was almost no vegetation regrowth as indicated by the low EVI2 pro- file during this period. For the years of 2007 and 2008 a typical spectral response for agricultural areas can be observed, characterized by a rapid increase followed by a rapid decrease of the vegetation index values indicating the well defined and short growth cycles of agricultural annual crops.

Figure 6 shows the seasonality of a selected point from an area that was deforested in 2004 in the National Park of Xingu, Mato Grosso state, Brazil. The visual analysis of the time series indicates a land conversion from forest to pastures. It can also be observed that the deforestation process started in the first quarter of 2004 and ended in the last quarter of the same year. It is interesting to note that the two areas observed in Figures 5 and 6 present different types of land use change that can be easily observed by analyzing the 10 years MODIS EVI2 time series. The double arrows illustrate the land use or land cover in the period. 


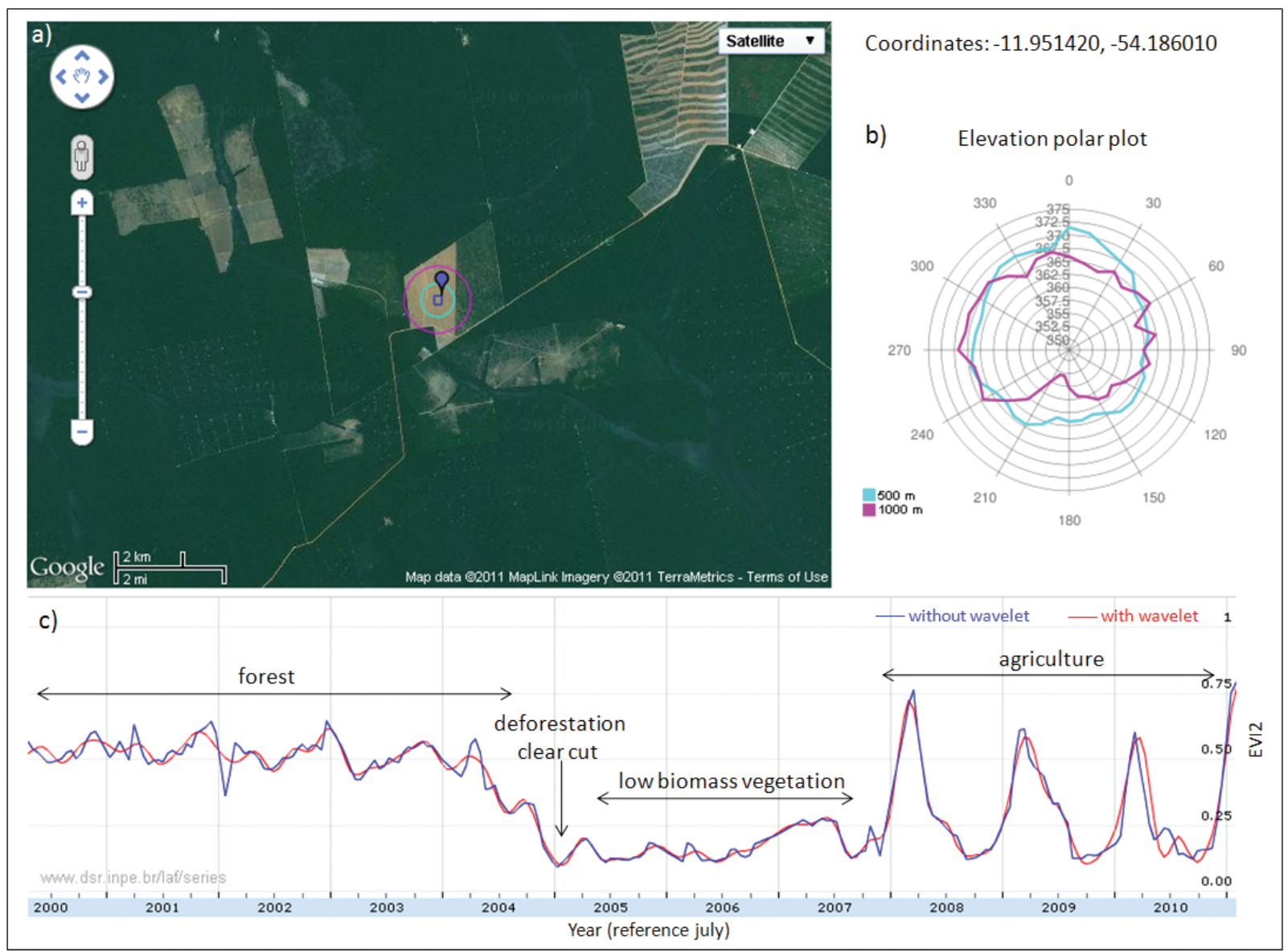

Figure 5 -a) GoogleMaps image; b) elevation polar plot; and c) EVI2 time series plot for the selected coordinated point.

It is also interesting to note that the two differently filtered EVI2 time series generated similar curves for the selected plots of Figures $5 \mathrm{c}$ and $6 \mathrm{c}$. A smoother curve is observed for the EVI2 with wavelet (red curve), and but no significant difference is observed for the without wavelet (blue curve) in terms of LULC change analysis. On the other hand the smoothed filtered EVI2 time series can be used in the data mining and other classification procedures when the high frequency signal is not interesting.

\subsection{Land Use and Land Cover Change Over Sugarcane}

Figure 7a shows a region with intense sugarcane cultivation in the municipality of Brotas, São Paulo state, Brazil. Figure 7c shows the dynamic of nine sugarcane crop years. With some knowledge on sugarcane cultivation several information can be extracted from the time series curve. A brief description of the sugarcane cultivation practices in this area can be given by the analyst in the following form. At the very beginning of the time series the low EVI2 values indicate bare soil over which the sugarcane was planted in the beginning of 2001. This sugarcane plant grew for about 18 months when it was harvested for the first time around July 2002. After the first cut the sugarcane ratoons were harvested once a year, around July, from 2003 to 2007. The sugarcane field was renovated in late 2007 when it was rotated with an annual summer crop followed by new sugarcane planted in late 2008 and harvested in mid 2009. More information about this plot can be obtained at http://www.dsr.inpe.br/laf/canasat/ [17].

The above description indicated that with a minimum of technical knowledge about sugarcane agricultural practices it is possible to the analyst recovering the 10 years history of specific plots and fields. This can be of great interest to certifiers that need to know the LULC change history.

\subsection{Land Use and Land Cover Change Over Savanna}

Figure 8 shows an agricultural region at the frontier of the savanna located in western Bahia state, Brazil. The region was originally covered by savanna and has been gradually converted 


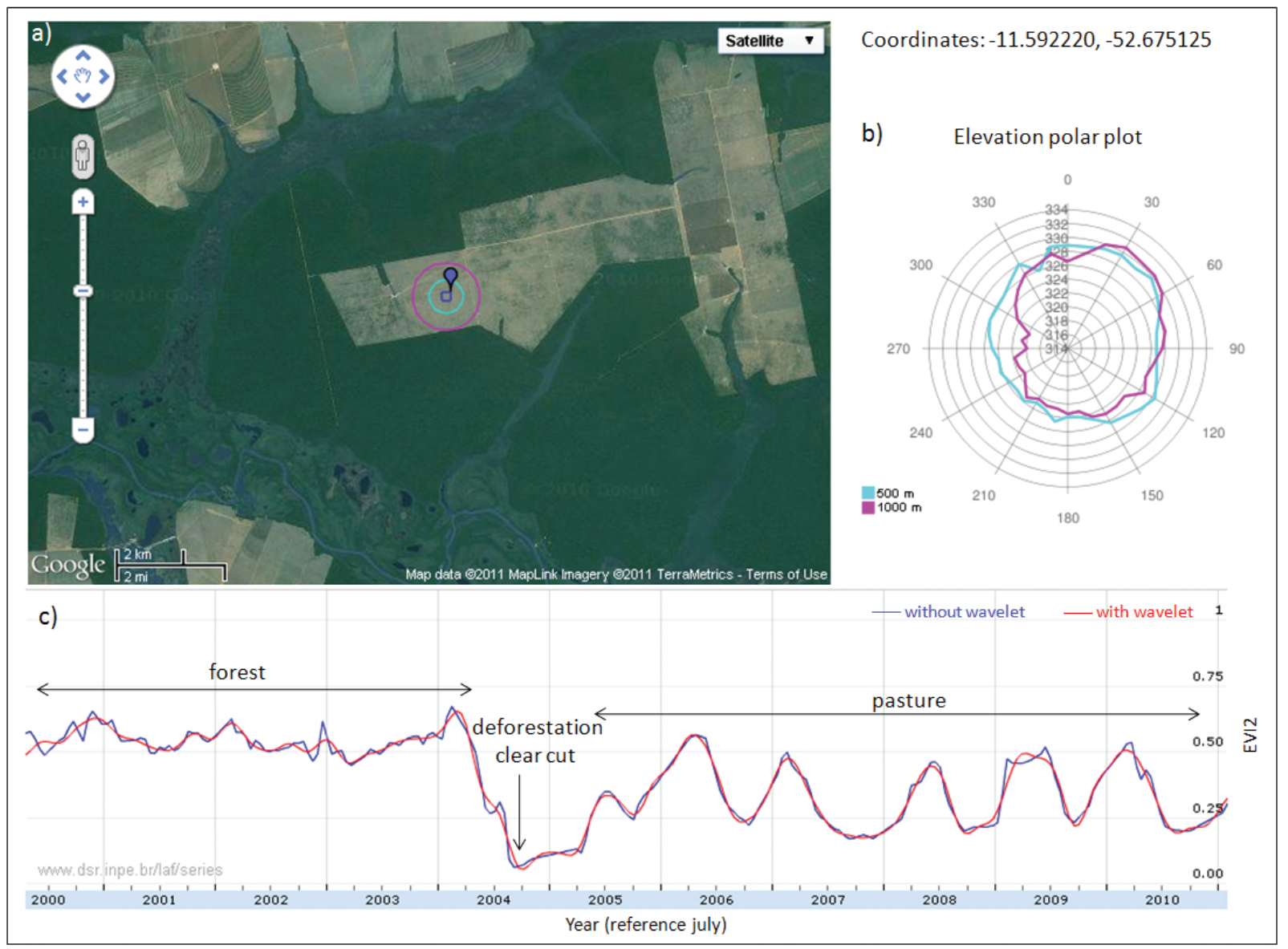

Figure 6 -a) GoogleMaps image; b) elevation polar plot; and c) EVI2 time series plot for selected coordinated point.

to intense agricultural land use. This region is characterized by large soybeans, corn, cotton and coffee plantations. Three time series over typical plots can be observed in Figures $8 c, 8 d$ and 8e. Figure $8 \mathrm{c}$ shows the typical behavior of a savanna with relative low values EVI2 and small amplitudes. Figure 8d presents the curve of a savanna area which was converted to agriculture during the 2007/2008 crop season. Figure 8 e shows the conversion of savanna to agriculture after 2002.

\section{GENERAL REMARKS AND FUTURE WORKS}

This work presented a visualization module for the virtual laboratory using the ten years history of MODIS EVI2 time series for the entire South America continent. The visualization module demonstrated to be useful for rapid land use and land cover change analysis, at the pixel level, over large regions. The smoothed filtered EVI2 time series using wavelet transformation could be used for checking dates of land use change such as date of deforestation, planting date of agricultural crops, seasonal effect on pasture land and others. Regarding to the integration with virtual globes such as Googlemaps, this work showed an innovation because it allows the public access and instantaneous visualization. This work can be extended for any geographical region since MODIS data are available for the entire globe.

Future works will be focused on providing quality parameters associated with each time-series, through an under-development validation procedure. Due to the area coverage, a near-real time open access techniques will be evaluated for allowing land cover types to be detected by any analyst with a GPS. Table 1 describes the main algorithms and tools for data analysis to be implemented in future virtual laboratory versions. A user friendely interface will be implemented to connect the Algorithm module and the Analysis module facilities with virtual laboratory users.

Next versions of the Virtual Laboratory of Remote Sensing Time Series can be implemented with other data sets such as temperature, rainfall, fraction components of linear mixture model and 


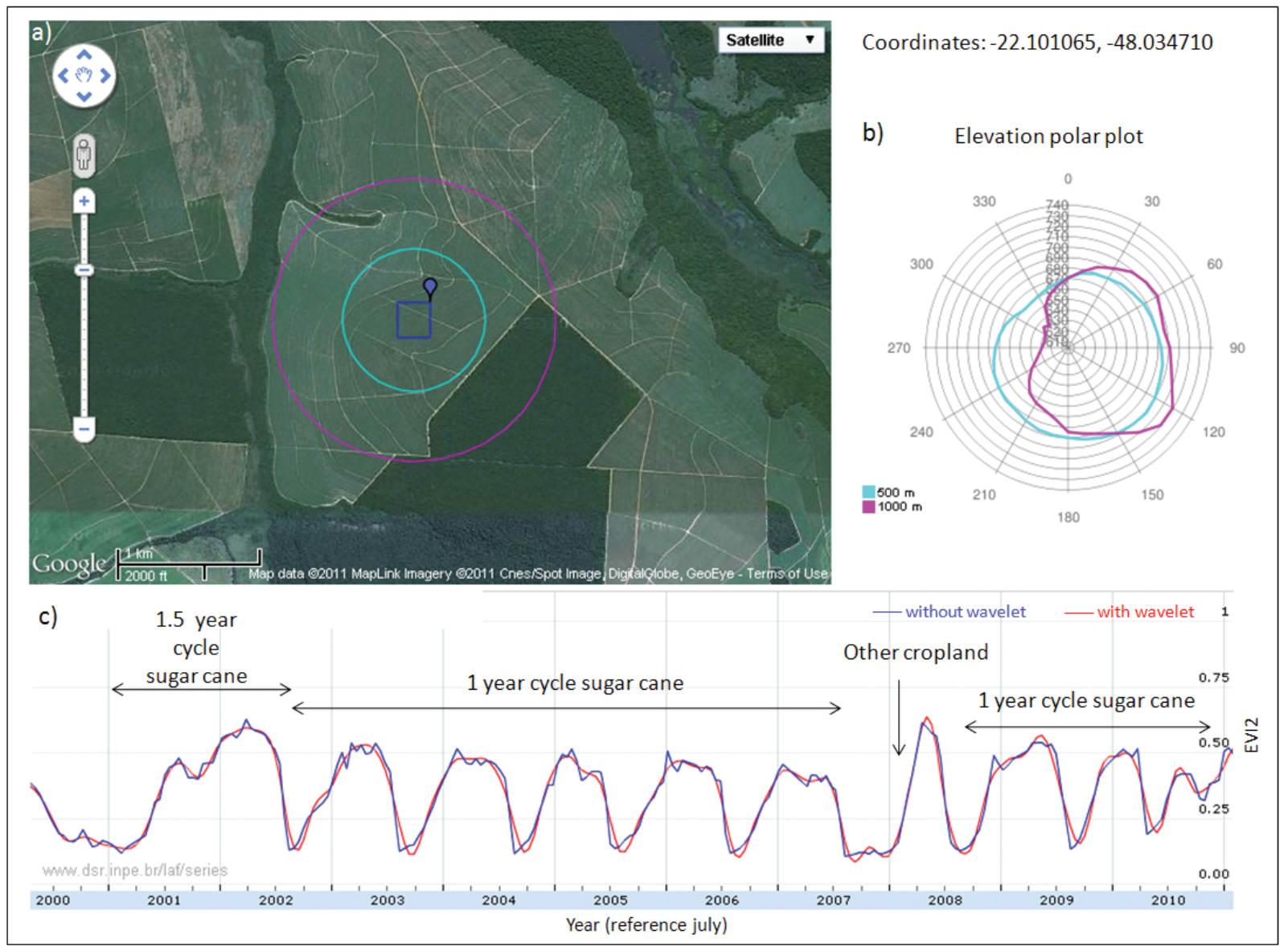

Figure 7 -a) GoogleMaps image; b) elevation polar plot; and c) EVI2 sugarcane time series plot for selected coordinated point.

Table 1 - Main algorithms and tools for data analysis to be implemented in the Virtual Laboratory of Remote Sensing Time Series.

\begin{tabular}{|c|c|}
\hline Algorithms and Analysis Tools & Applications \\
\hline $\begin{array}{l}\text { Time-Frequency Analysis Tools (Fourier, } \\
\text { Wavelets, Chiplets transforms) [18, 19, 20] }\end{array}$ & $\begin{array}{l}\text { Understand time series variability based } \\
\text { on spectral and temporal analysis tools }\end{array}$ \\
\hline Gradiente Pattern Analysis [21, 22, 23] & $\begin{array}{l}\text { Non linear advanced time series analysis } \\
\text { based on symmetric and structural concepts }\end{array}$ \\
\hline Detrended Fluctuation Analysis $[24,25]$ & $\begin{array}{l}\text { Non-linear advanced time series } \\
\text { analysis based on scale invariance concepts }\end{array}$ \\
\hline Cluster Analysis Tools [26, 27] & Dataset analysis and classifications \\
\hline $\begin{array}{l}\text { Support Vector Machines and } \\
\text { Decision Tree Classifiers [28, 29, 30] }\end{array}$ & $\begin{array}{l}\text { Temporal analysis and Land Use and } \\
\text { Land Cover Change classifications }\end{array}$ \\
\hline GIS file formats integration tools [31, 32] & Supplementary analysis \\
\hline Statistical regions analysis tools [33] & Regional and local focus analysis \\
\hline Dataset subset and download facilities & Peopleware and users facilities \\
\hline Metafile and Metadata usage [33] & $\begin{array}{l}\text { Ancillary data for image interpretation } \\
\text { and Land Use and Land Cover Analysis }\end{array}$ \\
\hline Seasonality tools [18] & $\begin{array}{l}\text { Compute the pos-processing products } \\
\text { such as: annual, monthly, regional } \\
\text { anomalies and phenology cycles. }\end{array}$ \\
\hline
\end{tabular}




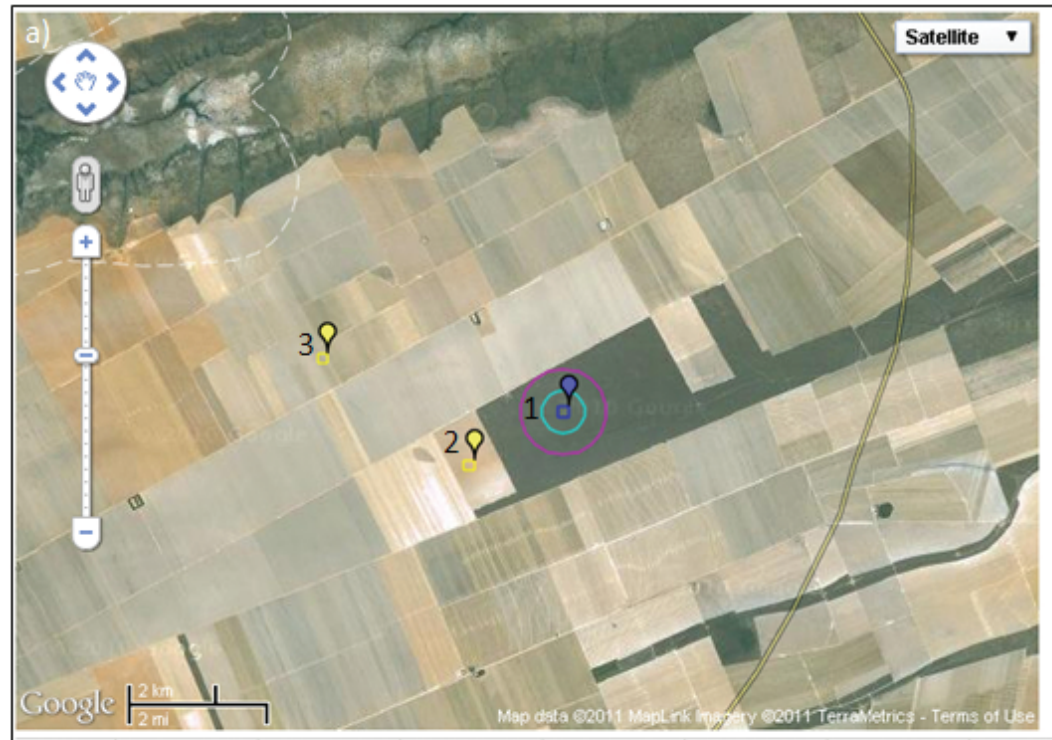

Coordinates: --12.562010, -46.095030

b) Elevation polar plot

c) (1) Point coordinates: (-12.562060, -46.095030$)$
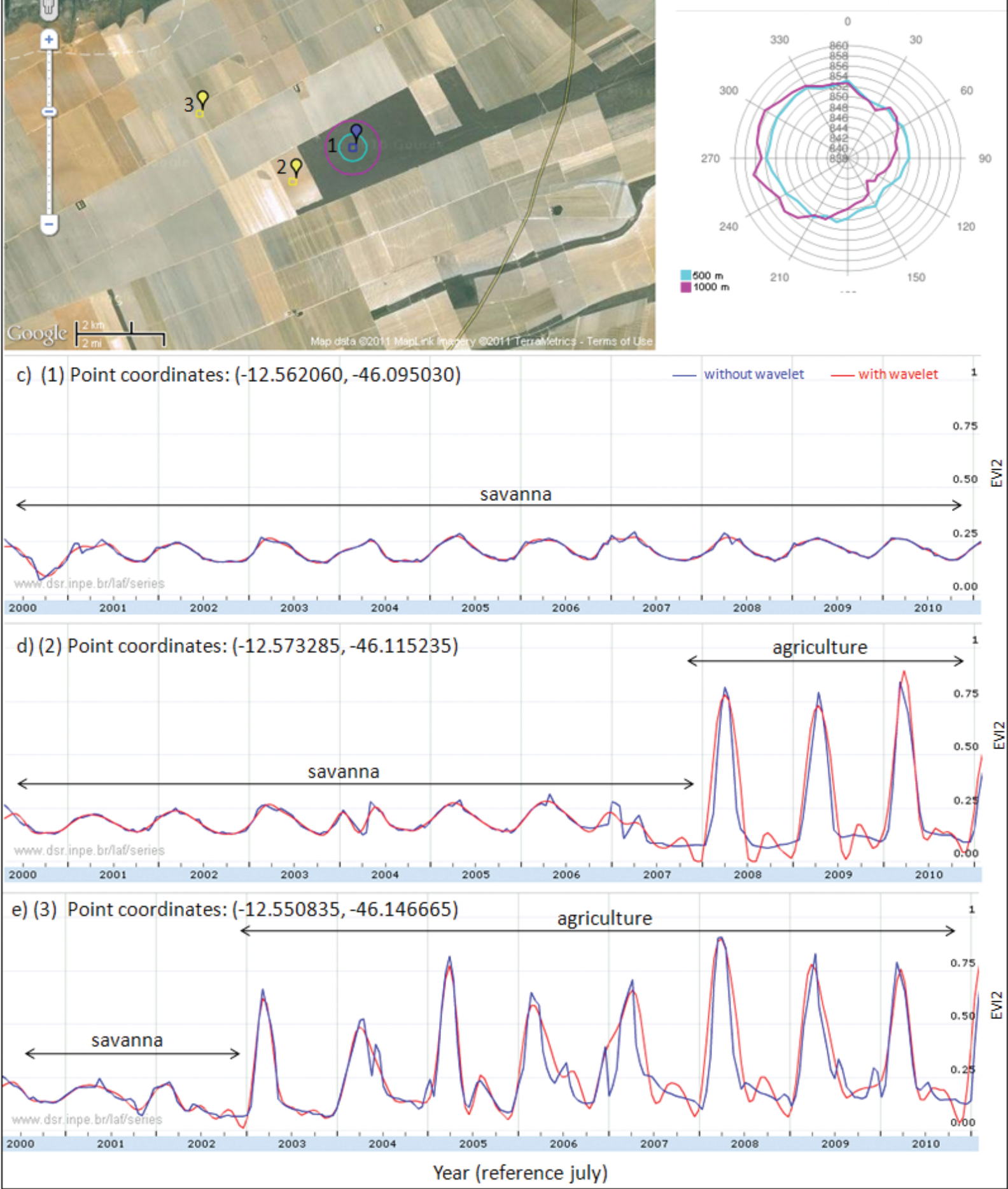

Figure 8 - a) GoogleMaps image; b) elevation polar plot; c) EVI2 time series plot for selected coordinated point 1, savanna area; d) EVI2 time series plot for selected coordinated point 2, deforestation area in 2007; and e) EVI2 time series plot for selected coordinated point 3, deforestation area in 2002. 
vegetation indices. The concept, protocols, hardware support and other software engineering specifications have been carried out to make the instantaneous visualization and analysis of time series a reality for remote sensing and general GIS users community.

\section{ACKNOWLEDGMENTS}

The authors thank CAPES (Coordenação de Aperfeiçoamento de Pessoal de Nível Superior), FAPESP (Fundação de Amparo à Pesquisa do Estado de São Paulo) and CNPq (Conselho Nacional de Desenvolvimento Científico e Tecnológico) agencies for partial financial support to the work, and INPE (Earth Observation OBT, Remote Sensing Division, DSR and Laboratory of Agriculture and Forest - LAF) for infrastructure and computing support. The MODIS data are distributed by the Land Processes Distributed Active Archive Center (LP DAAC), located at the U.S. Geological Survey (USGS) Earth Resources Observation and Science (EROS) Center (Ipdaac.usgs.gov). The author thanks the referees for their helpful suggestions concerning the presentation of this paper.

\section{REFERENCES}

[1] LAMBIN EF \& LINDERMAN M. 2006. Time series of remote sensing data for land change science. IEEE Transactions on Geoscience and Remote Sensing, 44(7): 1926-1928.

[2] DEFRIES RS, ASNER GP \& HOUGHTON RA. 2004. Ecosystems and Land Use Change. American Geophysical Union, Washington, DC.

[3] JUSTICE CO, TOWNSHEND JRG, VERMOTE EF, MASUOKA E, WOLFE RE, SALEOUS, N, ROY DP \& MORISETTE JT. 2002. An overview of MODIS Land data processing and product status. Remote Sensing of Environment, 83: 3-15.

[4] BUTLER D. 2006. Virtual globes: the web-wide world. Nature, 439(7078): 776-778.

[5] BALLAGH LM, RAUP BH, DUERR RE, KHALSA SJS, HELM C, FOWLER D \& GUPTE A. 2011. Representing scientific data sets in KML: Methods and challenges, Computers \& Geosciences, 37(1), Virtual Globes in Science, p. 57-64. ISSN 0098-3004, DOI: 10.1016/j.cageo.2010.05.004.

[6] CHIANG G, TOBY OH, DOVE MT, BOVOLO CI \& EWEN J. 2011. Geo-visualization Fortran library, Computers \& Geosciences, 37(1), Virtual Globes in Science, p. 65-74, ISSN 0098-3004, DOI: 10.1016/j.cageo.2010.04.012.

[7] NIELSON GM. 1991. Visualization in Scientific and Engineering Computation. IEEE Computer, 24(9): 58-66.

[8] EVA H, BELWARD A, EVARISTO M, DI BELLA C, GOND V, JONES S, SGRENZAROLI M \& FRITZ S. 2004. A land cover map of South America, Global Change Biology, 10: 731-744.
[9] JIANG Z, HUETE AR, DIDAN K \& MIURA T. 2008. Development of a two-band Enhanced Vegetation Index without a blue band. Remote Sensing of Environment, 112(10): 3833-3845.

[10] SAKAMOTO T, YOKOZAWA M, TORITANI H, SHIBAYAMA M, ISHITSUKA N \& OHNO H. 2005. A crop phenology detection method using time series MODIS data. Remote Sensing of Environment, 96(3-4): 366-374.

[11] THAYN JB \& PRICE KP. 2008. Julian dates and introduced temporal error in remote sensing vegetation phenology studies. International Journal of Remote Sensing, 29: 6045-6049.

[12] FREITAS RM \& SHIMABUKURO YE. 2008. Combining wavelets and linear spectral mixture model for MODIS satellite sensor time series analysis. JCIS - Journal of Computational Interdisciplinary Sciences, 1: 51-56.

[13] DAUBECHIES I. 1992. Ten lectures on wavelets. CBMS-NSF Regional Conference Series in Applied Mathematics 61, Philadelphia, PA. Soc. Ind. Appl. Math, 377 pp.

[14] MEYER Y. 1992. Wavelets and operators, Cambridge Studies in Advanced Math., vol. 37, Cambridge Univ. Press, Cambridge, 223 p.

[15] MALLAT S. 1989. A theory for multi resolution signal decomposition: the wavelet representation. IEEE Transactions on Pattern Analysis and Machine Intelligence, 11: 674-693.

[16] LAPOLA DM, SCHALDACH R, ALCAMO J, BONDEAU A, KOCH J, KOELKING C \& PRIESS JA. 2010. Indirect land-use changes can overcome carbon savings from biofuels in Brazil. Proceedings of the National Academy of Sciences, 107(8): 3388-3393.

[17] RUDORFF BFT, AGUIAR DA, SILVA WF, SUGAWARA LM, ADAMI M \& MOREIRA MA. 2010. Studies on the Rapid Expansion of Sugarcane for Ethanol Production in São Paulo State (Brazil) Using Landsat Data. Remote Sensing, 2: 1057-1076.

[18] MALLAT S. 1999. A wavelet tour of signal processing, $2^{\text {nd }}$ Edition, Academic Press.

[19] LE PENNEC E \& MALLAT S. 2005. Sparse Geometric Image Representation with Bandelets, IEEE Trans. on Image Processing, 14(4): 423-438.

[20] BOASHASH B. 2003. Time-Frequency Signal Analysis and Processing: A Comprehensive Reference, Oxford: Elsevier Science.

[21] ROSA RR, PONTES J, CHRISTOV CI, RAMOS FM, RODRIGUES NETO C, REMPEL EL \& WALGRAEF D. 2000. Physica A, 283: 156.

[22] ASSIREU AT, ROSA RR, VIJAYKUMAR NL \& LORENZZETTI JA. 2002. Gradient pattern analysis of short nonstationary time series: an application to Lagrangian data from satellite tracked drifters. Physica D, Elsevier, 169c: 397-403. 
[23] FREITAS RM, ROSA RR \& SHIMABUKURO YE. 2010. Using Gradient Pattern Analysis for land use and land cover change detection. In: International Geoscience and Remote Sensing Symposium (IGARSS), IEEE, Honolulu, 1: 3648-3651.

[24] PENG CK et al. 1994. Mosaic organization of DNA nucleotides. Phys Rev E, 49(2): 1685-1689.

[25] KANTELHARDT JW et al. 2001. Detecting long-range correlations with detrended fluctuation analysis. Phys A, 295(3-4): 441-454.

[26] DUDA RO, HART PE. 1973. Pattern Classification and Scene, AnaIysis, New York: John Wiley \& Sons, Inc.

[27] HARTIGAN JA. 1985. Statistical Theory in Clustering. Journal of Classification, 2: 63-76.

[28] THEODORIDIS S, KOUTROUMBAS K. 2009. Pattern Recognition, $4^{\text {th }}$ Edition, Academic Press.
[29] YANG T. 2006. Computational Verb Decision Trees. International Journal of Computational Cognition (Yang's Scientific Press), 4(4): 34-46.

[30] YUAN Y, SHAW MJ. 1995. Induction of fuzzy decision trees. Fuzzy Sets and Systems, 69: 125-139.

[31] LONGLEY P, GOODCHILD MF, MAGUIRE DJ, RHIND DW. 2005. Geographical information systems and science: John Wiley \& Sons Inc.

[32] LONGLEY P. 2008. To what extent are the fundamental spatial concepts that lie behind GIS relevant in design? In Spatial Concepts in GIS and Design. Santa Barbara, CA: UCSB.

[33] BRETHERTON FP, SINGLEY PT. 1994. Metadata: A User's View, Proceedings of the International Conference on Very Large Data Bases (VLDB). pp. 1091-1094. 